TITLE:

\title{
The functional effect of Gly209 and Ile213 substitutions on lysozyme activity of family 19 chitinase encoded by cyanophage Ma- LMM01
}

\section{AUTHOR(S):}

Hosoda, Naohiko; Kurokawa, Yoichi; Sako, Yoshihiko; Nagasaki, Keizo; Yoshida, Takashi; Hiroishi, Shingo

\section{CITATION:}

Hosoda, Naohiko ... [et al]. The functional effect of Gly209 and Ile213 substitutions on lysozyme activity of family 19 chitinase encoded by cyanophage Ma-LMM01. Fisheries Science 2011, 77(4): 665-670

\section{ISSUE DATE:}

2011-07

URL:

http://hdl.handle.net/2433/143681

\section{RIGHT:}

The final publication is available at www.springerlink.com; この論文は 出版社版でありません。引用の際には出版社版をご確認ご利用くださ $\omega_{\circ}$; This is not the published version. Please cite only the published version. 


\section{Title}

2 The functional effect of Gly209 and Ile213 substitutions on lysozyme activity of family

319 chitinase encoded by cyanophage Ma-LMM01

4

5 Authors

6 Naohiko Hosoda $\cdot$ Yoichi Kurokawa $\cdot$ Yoshihiko Sako $\cdot$ Keizo Nagasaki $\cdot$ Takashi

$7 \quad$ Yoshida $\cdot$ and Shingo Hiroishi

8

$9 \quad$ N. Hosoda

10 Departmennt of Marine Bioscience, Fukui Prefectural University, 1-1 Gakuen-cho,

11 Obama, Fukui 917-0003, Japan

12 E-mail: s0894004@s.fpu.ac.jp

13 Y. Kurokawa

14 Department of Bioscience, Fukui Prefectural University, 4-1-1 Matsuoka-Kenjojima,

15 Eiheiji-cho, Yoshida-gun, Fukui 910-1195, Japan

16 E-mail: kurokawa@fpu.ac.jp

17 Y. Sako

18 Graduate School of Agriculture, Kyoto University, Kyoto 606-8502, Japan

19 E-mail: sako@kais.kyoto-u.ac.jp

20 K. Nagasaki

21 National Research Institute of Inland Sea, Fisheries Research Agency, 2-17-5 Maruishi,

22 Hatsukaichi, Hiroshima 739-0452, Japan

23 E-mail: nagasaki@affrc.go.jp

24 S. Hiroishi

25 Departmennt of Marine Bioscience, Fukui Prefectural University, 1-1 Gakuen-cho,

26 Obama, Fukui 917-0003, Japan

$27 \quad$ E-mail: hiroishi@fpu.ac.jp

28

29

Corresponding author

30 T. Yoshida

31 Mailing address: Laboratory of Marine Microbiology, Graduate School of Agriculture,

32 Kyoto University, Kyoto 606-8502, Japan.

33 Tel: +81-75-753-6218; Fax: +81-75-753-6226

34 E-mail: yoshiten@kais.kyoto-u.ac.jp 


\section{Abstract}

ORF69 in the cyanophage infecting Microcystis aeruginosa, Ma-LMM01, shows homology to the family 19 chitinases where the catalytic domain has structural similarity to lysozyme. Chitinases hydrolyze chitin, a $\beta$-1, 4-linked monopolymer of $\mathrm{N}$-acetylglucosamine (GlcNAc); whereas lysozymes hydrolyzes peptidoglycan, alternating $\beta$-1, 4-linked copolymers of $N$-acetylmuramic acid (MurNAc) and GlcNAc.

Using amino acid sequence comparison to ORF69, the putative sugar binding residues, Gln162 and Lys165, from the barley chitinase (the model enzyme for the family 19 chitinases) corresponding to subsites -4 and -3 were found to be replaced with Gly209 and Ile213, respectively, in ORF69. To analyze their contribution to substrate binding affinity, ORF69 was cloned into Escherichia coli; and two mutant proteins G209Q and I213K were prepared using site-directed mutagenesis. The wild-type gene product (gp69) showed both lysozyme and chitinase activities. In contrast, the I213K mutant showed a decrease (70\%) in lysozyme activity and a significant increase (50\%) in chitinase activity; whereas, the G209Q mutant almost completely abolished both enzyme activities. The data suggest the Ile213 residue is involved in recognizing the substrate MurNAc; and Gly209 has significant contribution in chitinase and lysozyme activities for the wild-type gp69. 


\section{$54 \quad$ Keywords}

55 Microcystis, cyanophage, family 19 chitinase, site-directed mutagenesis 


\section{Introduction}

Throughout the world, Microcystis aeruginosa is one of the common

bloom-forming species in eutrophic freshwaters. Some strains produce cyclic peptide toxins called microcystins that cause serious health problems in water management [1].

Previously we isolated a cyanophage, Ma-LMM01, infecting the toxic M. aeruginosa strain NIES298 [2]. The genome of Ma-LMM01 contains 184 ORFs [3]. The majority of the predicted genes have no detectable homologues in present databases including other Myoviridae; and thus Ma-LMM01 was assigned as a member of a new lineage of the Myoviridae family [3, 4]. Of the ORFs, ORF69 is predicted to encode for a member of the family 19 chitinases whose catalytic domain has structural similarity to lysozyme [5].

Chitinase (EC 3.2.1.14) is a glycoside hydrolase that hydrolyzes chitin, a linear $\beta$-1, 4-linked monopolymer of $N$-acetylglucosamine (GlcNAc). Based on structures and catalytic mechanisms, the chitinases are classified into two families, 18 and $19[6,7]$.

Family 18 chitinases are widely distributed in a variety of organisms such as bacteria, fungi, bacteriophages, animals and higher plants (classes III and V); whereas family 19 chitinases are found only in higher plants (classes I, II and IV). Recently, however, some members of the family 19 chitinases have been found in genomes of 
actinobacteria, proteobacteria, nematodes and bacteriophages [8]. Based on amino acid

separated into five clusters (clusters I to V) [8]. Of these, cluster III of the family 19

chitinases are most distantly related to the other clusters [8]. The cluster III family 19 of

chitinases consists only of those from proteobacteria and bacteriophages and the genes

in proteobacteria are often found within the phage-related regions. The cluster III family

19 chitinase genes in PA0629 from Pseudomonas aeruginosa and PFL_1227 from $P$.

fluorescens Pf-5 are located within a region of one of the variants of a defective phage

(pyocin) and prophage, respectively. Their recombinant proteins have lysozyme activity that hydrolyses peptidoglycans, alternating $\beta$-1, 4-linked residues of $N$ - acetylmuramic acid (MurNAc) and GlcNAc $[9,10]$. and substrate-binding residues using crystal structure analyses, e.g. those from barley residues were replaced in the putative substrate-binding residues of ORF69 when compared to the other family 19 chitinases. Here, we determined the lysozyme and 
examined the function of the two residues in recognition of the substrates, chitin and peptidoglycan, using site-directed mutagenesis.

\section{Materials and methods}

\section{Cloning of ORF69 and derivatives}

The genomic DNA of Ma-LMM01 was purified as described previously [2]. To isolate the full sequence of the ORF69 gene, a PCR reaction was performed with a forward primer MaPOrf69InF and a reverse primer MaPOrf69InR1 containing EcoRI site (Table 1). The PCR was performed in a $50 \mu$ containing 200 ng Ma-LMM01 DNA, $10 \mu \mathrm{M}$ primers, $250 \mu \mathrm{M}$ each dNTPs, 1X PCR buffer for KOD-plus- and $1 \mathrm{U}$ KOD-Plus- (TOYOBO, Osaka, Japan). The reaction conditions were: 2 min initial denaturing at $94{ }^{\circ} \mathrm{C}$ followed by 35 cycles: $94{ }^{\circ} \mathrm{C}$ for $15 \mathrm{~s}, 45^{\circ} \mathrm{C}$ for $30 \mathrm{~s}$ and $68^{\circ} \mathrm{C}$ for 90 s. The reaction mixture was purified using a Wizard ${ }^{\circledR}$ SV Gel and PCR Clean-Up System (Promega, Madison, WI). The pTrc-OmpA vector was fused with the OmpA signal sequences upstream of a multiple cloning site; thus the resulting expressed protein is transported to the periplasm in the transformants [15]. The purified DNA fragments were digested with EcoRI (TOYOBO) and cloned into expression vector pTrc-OmpA. The coding region of the ORF69 was inserted downstream of the OmpA 
110 signal sequence yielding pTrc-OmpA-ORF69. E. coli JM109 (TOYOBO) was

111 transformed with the pTrc-OmpA-ORF69; and the transformant was selected on LB

112 plates containing $100 \mu \mathrm{g} / \mathrm{ml}$ carbenicillin disodium salt (Nacalai Tesque, Kyoto, Japan)

113 and $0.5 \%$ glucose. The DNA sequence of the resultant plasmids was verified using the

114 primers Trc-F and Trc-R2 (Table 1).

\section{Site-directed mutagenesis}

Three mutant proteins (G209Q, I213K and E122A) were constructed using

117 PCR-based site-directed mutagenesis. The mutagenesis primers are shown in Table 1.

118 The PCR reaction mixtures contained $100 \mathrm{ng}$ plasmid DNA template, 10 pmol each of

119 the forward and reverse primers containing the desired mutation, $2 \mathrm{mM}$ dNTPs, reaction

120 buffer and PfuUltra High-Fidelity DNA polymerase (Stratagene, La Jolla, CA). The

reaction mixture was subjected to 20 cycles of PCR $\left(95{ }^{\circ} \mathrm{C}\right.$ for $30 \mathrm{~s} ; 55^{\circ} \mathrm{C}$ for $1 \mathrm{~min}$; and

$68^{\circ} \mathrm{C}$ for $12 \mathrm{~min}$ ); then, the resultant plasmids were digested with $D p n$ I. Finally, the

mutated plasmids were transformed into E. coli JM109 and expressed.

124 Preparation of culture supernatant from transformants. 
128 diluted to $100 \mathrm{ml}$ of fresh $\mathrm{LB}$ medium and grown with shaking at $30{ }^{\circ} \mathrm{C}$ until the

$129 \mathrm{OD}_{660 \mathrm{~nm}}=0.5$. Protein expression was induced adding

130 isopropyl- $\beta$-D-thiogalactopyranoside (IPTG) to a final concentration of $0.1 \mathrm{mM}$. After

131 growth for another $6 \mathrm{~h}$, the supernatant of two consecutive centrifugations $(15,000 \mathrm{~g}, 5$

$132 \min$, at $4{ }^{\circ} \mathrm{C}$ ) was stored as the culture supernatant at $-20{ }^{\circ} \mathrm{C}$ until used. The pelleted

133 cells were resuspended in $50 \mathrm{mM}$ sodium phosphate buffer ( $\mathrm{pH}$ 6.2) and disrupted using

134 sonication. After centrifugation, the crude extracts were also stored at $-20{ }^{\circ} \mathrm{C}$. Amount

135 of total protein was measured by method of Bradford with BSA as a standard [16].

136 Enzymatic activities of culture supernatant from $\boldsymbol{E}$. coli cells expressing the

137 wild-type ORF69 and its mutants.

138 (i) Lysozyme activity

139

Lyophilized cells of Micrococcus lysodeikticus ATCC4698 (Nacalai) were

140 re-suspended at a concentration of $0.25 \mathrm{mg} / \mathrm{ml}$ in $10 \mathrm{ml}$ of $50 \mathrm{mM}$ sodium phosphate

141 buffer (pH 6.2); then, $100 \mu \mathrm{g}$ of a culture supernatant (see above) was added to $2 \mathrm{ml}$ of

142 the M. lysodeikticus cell suspension. Cell lysis was measured continuously by

143 monitoring the decrease in turbidity $\left(\mathrm{OD}_{660 \mathrm{~nm}}\right)$ using a Ultraspec 2100 pro (GE

144 Healthcare, Buckinghamshire, UK) for 15 minutes at $37{ }^{\circ} \mathrm{C}$. Lysozyme activity was

145 calculated from the linear portion of the digestion graph representing absorbance versus 
146 time. One unit of enzyme activity was defined as the amount of enzyme causing an

147 absorbance decrease of $0.01 \mathrm{OD}_{660 \mathrm{~nm}}$ per min at $37^{\circ} \mathrm{C}[17]$.

148 (ii) Chitinase activity $p$ NP-(GlcNAc) $)_{\mathrm{n}}(\mathrm{n}=2$ to 5) (Yaizu Suisan Chemical Co. Ltd., Shizuoka, Japan) as the

$154 \mathrm{~min}$ after addition at $37{ }^{\circ} \mathrm{C}$. The reaction was stopped by adding $250 \mu 10.2 \mathrm{M} \mathrm{Na}_{2} \mathrm{CO}_{3}$ and the released $p$-nitrophenol was measured at $\mathrm{OD}_{420 \mathrm{~nm}}$. One unit of chitinase activity was defined as the amount of enzyme causing $1 \mu \mathrm{mol}$ releasing of $p$-nitrophenol per min at $37^{\circ} \mathrm{C}$.

\section{$158 \quad$ Results}

The amino acid sequence of ORF69 
164 chitinase (cd00325). There are two catalytic residues and seven putative sugar binding

165

166

167

168

169

170

residues in the family 19 chitinases.

The position of the 161-166 residues (the 161-166 loop) in the cluster I barley

family 19 chitinase contains two polar amino acids (Gln162 and Lys165) (Fig. 1) [20].

Gln162 and Lys165 are thought to form the substrate-binding site, namely subsite -4

and -3 , respectively (subsites are numbered according to the standard nomenclature;

cleavage occurs between the sugar units bound in subsites -1 and +1 [21]). These

residues in ORF69 and other cluster III family 19 chitinases are replaced with the

non-polar amino acids, Gly209 and Ile213. Therefore, we predicted mutations in

residues Gly209 and Ile213 of ORF69 would affect the recognition of substrates. To

confirm this hypothesis, site-directed mutagenesis was performed.

\section{Lysozyme activity of gp69 and its mutants}

Based on the vector pTrc-OmpA-ORF69 encoding the wild-type ORF69

enzyme (gp69), two vectors encoding mutants in the putative sugar biding site (G209Q,

I213K) and one in the catalytic site (E122A) were constructed.

The growth of transformants was monitored measuring the change in $\mathrm{OD}_{660 \mathrm{~nm}}$.

After induction with IPTG, the OD value of both transformants containing

pTrc-OmpA-ORF69 and pTrc-OmpA-ORF69-I213K declined about 30\% from 4 to $8 \mathrm{~h}$ 
182 (data not shown). In contrast, normal growths were observed in transformants

containing pTrc-OmpA-ORF69-G209Q and pTrc-OmpA-ORF69-E122A.

In transformants containing either pTrc-OmpA-ORF69 or

pTrc-OmpA-ORF69-I213K, induction of protein expression caused cell lysis and most

of the lysozyme activities were observed in the culture supernatant fraction (data not

activity was observed in both culture supernatant fractions and crude protein from

pelleted cells (data not shown). In addition, a 10-fold concentration of the crude extracts

lysozyme activity. Lysozyme activity from the mutant protein, E122A (having a mutation in the catalytic site) was not detected.

Chitinase activity of gp69 and its mutants digesting chitooligosaccharides. 
200 the substrate (Fig. 2). Whereas, the hydrolytic activity to $p \mathrm{NP}-(\mathrm{GlcNAc})_{5}$ was

201 approximately one-half compared to $p \mathrm{NP}-(\mathrm{GlcNAc})_{3}$; and the hydrolysis activity for

$202 p \mathrm{NP}-(\mathrm{GlcNAc})_{4}$ was not detected (Fig. 2). Compared to the gp69, the hydrolytic activity

203 of mutant protein $\mathrm{I} 213 \mathrm{~K}$ had approximately a 1.3 -fold increase using $p \mathrm{NP}-(\mathrm{GlcNAc})_{3}$

204 and the hydrolytic activity to $p$ NP-(GlcNAc) $)_{4}$ was increased. Thus, the $\mathrm{I} 213 \mathrm{~K}$ mutation

205 increased the hydrolyzing activity towards $p$ NP- $(\mathrm{GlcNAc})_{3}$ and $p \mathrm{NP}-(\mathrm{GlcNAc})_{4}$ even

206 though the lysozyme activity of $\mathrm{I} 213 \mathrm{~K}$ was the $30 \%$ of that of wild-type (Table 2 ). In

207 contrast, the mutant protein, G209Q in both fractions, showed no detectable activity

208 towards any substrate. In addition, a 10-fold concentration of the crude extracts of

209 G209Q did not show chitinase activities (data not shown).

\section{Discussion}

We tried to construct various vectors for the expression of ORF69 where

spontaneous mutations were observed in the cloned sequences. This was possibly due to

the toxicity of the gene products for E. coli [22]. We obtained only one clone with the

OmpA signal-fused protein that was guided to the periplasmic space of the E. coli cell.

216 For this reason, crude extracts from the transformants were used in the enzymatic

experiments. 
various sizes of chitooligomers [23]. However, the release of $p$-nitrophenol from the

gp69 using the chitooligosaccharides as substrate suggests the wild-type gp69 is not has six subsites (from -4 to +2) [24]. Also, the subsite structures of higher plant family or $(-3)(-2)(-1)(+1)(+2)(+3)[25]$ except for those from Carica papaya [26] and Picea abies (Norway spruce) [27]. In HEWL, the corresponding subsite -3 is known to be responsible for interaction with MurNAc [24]. Combined, our data suggests the Ile213 residue corresponding to subsite -3 in ORF69 contributes to the interaction with MurNAc and the replacement of Ile213 with Lys may emphasize the affinity for $p \mathrm{NP}-(\mathrm{GlcNAc})_{3}$ and $p \mathrm{NP}-(\mathrm{GlcNAc})_{4}$ than for M. lysodeikticus. Whereas, the I213K mutation decreased the hydrolyzing activity to $p \mathrm{NP}-(\mathrm{GlcNAc})_{2}$ and $p \mathrm{NP}-(\mathrm{GlcNAc})_{5}$ where one possible explanation is interference of substrate access to the catalytic site due to the small oligosaccharides but we do not have any useful data concerning this hypothesis. The substitution of Gly209 to Gln caused a significant decrease in both 
236 lysozyme and chitinase activities. There is a possibility the single amino acid

237 replacement altered the conformation of recombinant protein G209Q [28]. Further study

238 is required to determine the effect of the Gly209 residue in conformational changes.

240 genes in bacteriophages) were in the current database [8, 29]. Two residues, Asn124 and

241 Lys 165 (according to the barley family 19 chitinase numbering), are presumed to be

242 responsible for the subsite -3 activity. These residues are highly conserved among

243 family 19 chitinases [20]. In ORF69 of Ma-LMM01, the amino acids corresponding to

244 the Lys 165 residue in 15 genes of the 19 cluster III family 19 chitinases are replaced

245 with non-polar amino acids. In the remaining four genes, the amino acids corresponding

246 to Lys165 is replaced with a Tyr residue. Further research focusing on the role of the Tyr

247 residue is necessary to determine its contribution in sugar binding.

higher plants to bacteria $[29,30]$. In the evolutionary history of the family 19 chitinases, 


\section{Acknowledgement}

253 This study was supported by a Grant-in-Aid for Science Research (No. 20310045). NH

254 is a research fellow supported by the Japan Society for the Promotion of Science for

255 Young Scientists (No. 218877). 


\section{References}

1. Codd GA, Lindsay J, Young FM, Morrison LF, Metcalf JS (2005) Harmful Cyanobacteria. In: Huisman J et al (eds) Harmful Cyanobacteria. Springer, Netherlands, pp 1-23

2.Yoshida T, Takashima Y, Tomaru Y, Shirai Y, Takao Y, Hiroishi S, Nagasaki K (2006) Isolation and characterization of a cyanophage infecting the toxic cyanobacterium Microcystis aeruginosa. Appl Environ Microbiol 72:1239-1247

3. Yoshida T, Nagasaki K, Takashima Y, Shirai Y, Tomaru Y, Takao Y, Sakamoto S, Hiroishi S, Ogata H (2008) Ma-LMM01 infecting toxic Microcystis aeruginosa illuminates diverse cyanophage genome strategies. J Bacteriol 190:1762-1772

4. Lavigne R, Darius P, Summer EJ, Seto D, Mahadevan P, Nilsson AS, Ackermann HW, Kropinski AM (2009) Classification of Myoviridae bacteriophages using protein sequence similarity. BMC Microbiol 9:224

5. Monzingo AF, Marcotte EM, Hart PJ, Robertus JD (1996) Chitinases, chitosanases, and lysozymes can be divided into procaryotic and eucaryotic families sharing a conserved core. Nat Struct Biol 3:133-140

6. Henrissat B (1991) A classification of glycosyl hydrolases based on amino acid sequence similarities. Biochem J 280:309-316

7. Henrissat B, Bairoch A (1993) New families in the classification of glycosyl hydrolases based on amino acid sequence similarities. Biochem J 293:781-788

8. Kawase T, Saito A, Sato T, Kanai R, Fujii T, Nikaidou N, Miyashita K, Watanabe T (2004) Distribution and phylogenetic analysis of family 19 chitinases in Actinobacteria. Appl Environ Microbiol 70:1135-1144

9. Nakayama K, Takashima K, Ishihara H, Shinomiya T, Kageyama M, Kanaya S, Ohnishi M, Murata T, Mori H, Hayashi T (2000) The R-type pyocin of Pseudomonas aeruginosa is related to P2 phage, and the F-type is related to lambda phage. Mol Microbiol 38:213-231 10. Mavrodi DV, Loper JE, Paulsen IT, Thomashow LS (2009) Mobile genetic elements in the genome of the beneficial rhizobacterium Pseudomonas fluorescens Pf-5. BMC Microbiol 9:8

11. Hart PJ, Pfluger HD, Monzingo AF, Hollis T, Robertus JD (1995) The refined crystal structure of an endochitinase from Hordeum vulgare L. seeds at 1.8 A resolution. J Mol Biol 248:402-413

12. Hahn M, Hennig M, Schlesier B, Hohne W (2000) Structure of jack bean chitinase. Acta Cryst D56:1096-1099 
13. Kezuka Y, Ohishi M, Itoh Y, Watanabe J, Mitsutomi M, Watanabe T, Nonaka T (2006) Structural studies of a two-domain chitinase from Streptomyces griseus HUT6037. J Mol Biol 358:472-484

14. Hoell IA, Dalhus B, Heggset EB, Aspmo SI, Eijsink VG (2006) Crystal structure and enzymatic properties of a bacterial family 19 chitinase reveal differences from plant enzymes. FEBS J 273:4889-4900

15. Kurokawa Y, Yanagi H, Yura T (2001) Overproduction of bacterial protein disulfide isomerase (DsbC) and its modulator (DsbD) markedly enhances periplasmic production of human nerve growth factor in Escherichia coli. J Biol Chem 276:14393-14399

16. Bradford MM (1976) A rapid and sensitive method for the quantitation of microgram quantities of protein utilizing the principle of protein-dye binding. Anal Biochem 72:248-254

17. Wang SL, Chang WT (1997) Purification and characterization of two bifunctional chitinases/lysozymes extracellularly produced by Pseudomonas aeruginosa K-187 in a shrimp and crab shell powder medium. Appl Environ Microbiol 63:380-386

18. Honda Y, Taniguchi H, Kitaoka M (2008) A reducing-end-acting chitinase from Vibrio proteolyticus belonging to glycoside hydrolase family 19. Appl Microbiol Biotechnol 78:627-634

19. Marchler-Bauer A, Anderson JB, Chitsaz F, Derbyshire MK, DeWeese-Scott C, Fong JH, Geer LY, Geer RC, Gonzales NR, Gwadz M, He S, Hurwitz DI, Jackson JD, Ke Z, Lanczycki CJ, Liebert CA, Liu C, Lu F, Lu S, Marchler GH, Mullokandov M, Song JS,

Tasneem A, Thanki N, Yamashita RA, Zhang D, Zhang N, Bryant SH (2009) CDD: specific functional annotation with the Conserved Domain Database. Nucleic Acids Res 37:205-210

20. Brameld KA, Goddard WA, 3rd (1998) The role of enzyme distortion in the single displacement mechanism of family 19 chitinases. Proc Natl Acad Sci USA 95:4276-4281

21. Davies GJ, Wilson KS, Henrissat B (1997) Nomenclature for sugar-binding subsites in glycosyl hydrolases. Biochem J 321:557-559 22. Perry LJ, Heyneker HL, Wetzel R (1985) Non-toxic expression in Escherichia coli of a plasmid-encoded gene for phage T4 lysozyme. Gene 38: 259-264

23. Robertus JD, Monzingo AF (1999) The structure and action of chitinases. EXS 87:125-135

24. Fukamizo T (2000) Chitinolytic enzymes: catalysis, substrate binding, and their application. Curr Protein Pept Sci 1:105-124 
25. Honda Y, Fukamizo T (1998) Substrate binding subsites of chitinase from barley seeds and lysozyme from goose egg white. Biochim Biophys Acta 1388:53-65

26. Huet J, Rucktooa P, Clantin B, Azarkan M, Looze Y, Villeret V, Wintjens R (2008) X-ray structure of papaya chitinase reveals the substrate binding mode of glycosyl hydrolase family 19 chitinases. Biochemistry 47:8283-8291

27. Ubhayasekera W, Rawat R, Ho SW, Wiweger M, Von Arnold S, Chye ML, Mowbray SL (2009) The first crystal structures of a family 19 class IV chitinase: the enzyme from Norway spruce. Plant Mol Biol 71:277-289

28. Gilbert HJ, Drabble WT (1980) Complementation in vitro between guaB mutants of Escherichia coli K12. J Gen Microbiol 117:33-45

29. Udaya Prakash NA, Jayanthi M, Sabarinathan R, Kangueane P, Mathew L, Sekar K (2010) Evolution, homology conservation, and identification of unique sequence signatures in GH19 family chitinases. J Mol Evol 70:466-478

30. Watanabe T, Kanai R, Kawase T, Tanabe T, Mitsutomi M, Sakuda S, Miyashita K (1999) Family 19 chitinases of Streptomyces species: characterization and distribution. Microbiology 145:3353-3363

31. Tamura K, Dudley J, Nei M, Kumar S (2007) MEGA4: Molecular Evolutionary Genetics Analysis (MEGA) software version 4.0.

Mol Biol Evol 24:1596-1599 


\section{Tables}

317 Table 1. Plasmids and primers used in this study

\begin{tabular}{|c|c|c|}
\hline Plasmids or primers & Characteristics or sequences (5' to 3') & Sources or references \\
\hline Plasmids & & \\
\hline pTrc-OmpA & $\mathrm{Amp}^{\mathrm{R}}$, lacI ${ }^{\mathrm{q}}$, ori (pBR322), trcP, $\operatorname{rrmB} \mathrm{T} 1 \mathrm{~T} 2$ terminator & Kurokawa, et al., [15] \\
\hline & 52314 to 53069 from cyanophage Ma-LMM01 & This study \\
\hline pTrc-OmpA-ORF69-G209Q & Substitute of ORF69 Gly209 to Gln209 & This study \\
\hline pTrc-OmpA-ORF69-I213K & Substitute of ORF69 Ile213 to Lys213 & This study \\
\hline Primers & & \\
\hline MaPOrf69InF & CTA AGA AAC ATT GAT AGA GC & This study \\
\hline MaPOrf69InR $1^{\text {a) }}$ & CGG AAT TCT CAT GTC AGC ACC GCC TGT A (EcoRI) & This study \\
\hline ORF69-E122A-F & CAG CTG ATG CAC GCG TCA $G G G$ AAC CTA CG & This study \\
\hline ORF69-E122A-R ${ }^{\mathrm{b})}$ & CGT AGG TTC CCT GAC GCG TGC ATC AGC TG & This study \\
\hline ORF69-I213K-R ${ }^{\mathrm{b})}$ & TTT ATA TCA TTC TTG TCT GCC TTT TCA TTT AGC CCC CGT GTT C & This study \\
\hline Trc-F & ACA TCA TAA CGG TTC TGGC & Kurokawa, et al., [15] \\
\hline Trc-R2 & CAA ATTC TGT TTT ATC AGA CC & Kurokawa, et al., [15] \\
\hline
\end{tabular}

339 
340 Table 2. Lysozyme activity of the culture supernatant of E. coli cells expressing the 341 wild-type gp69 and its mutants.

342

343

344

Protein Activity (U/ mg) Relative activity (\%)

345 G209Q $61.3 \pm 17.2$ 100

$346 \quad \mathrm{I} 213 \mathrm{~K}$$$
1.8
$$

$347 \quad$ E122A

$$
18.1 \pm 12.9
$$

29.5

348 Vector

ND

349 HEWL*

ND

350

$1.6 \pm 0.01$

2.6

351 The activity was measured by the decrease in absorbance at $\mathrm{OD}_{660 \mathrm{~nm}}$. The reaction

352 mixtures were incubated in $50 \mathrm{mM}$ sodium phosphate buffer, pH6.2 at $37{ }^{\circ} \mathrm{C}$. The data 353 are the means of three independent assays \pm SD. -, Activity not detected. *, Activities of 354 hen egg white lysozyme (HEWL; 0.6 $\mu$ g) was used as positive control. One unit of 355 enzyme activity was defined as the amount of enzyme that causes an absorbance 356 decrease of 0.01 . 


\section{Figure legends}

358

359

360

361

362

363

364

Figure 1. Alignment of amino acid sequences for the catalytic domains of family 19 chitinases. Sequence alignment was performed using MEGA version 4 software [31]. Residues conserved in the sequences are indicated by black backgrounds, whereas residues conserved in $>80$ and $>60 \%$ of the proteins examined are indicated by white type on a dark gray background and by black type on a light gray back ground, respectively. The two catalytic amino acid residues from the family 19 chitinases are indicated by closed triangles. Residues predicted to interact with saccharide molecules in theoretical models of the barley chitinase/ (GlcNAc) ${ }_{6}$ complex [19] are indicated by closed circles. The 161-166 residues (using the numbering of the barley enzyme; see text) are indicated by dots above the sequence. Based on higher plant and Streptomyces chitnase, the putative secondary structure assignments are indicated with " $h$ " for $\alpha$-helix and "s" in the $\beta$-strand. ORF69, Ma-LMM01 ORF69 (accession no. YP_851083);

PA0629, lytic enzyme of $P$. aeruginosa PAO1 (NP_249320); putative lytic enzyme of ORF_PML14, P. aeruginosa (YP_788803); PFL_1227, lytic enzyme of $P$. fluorescens Pf-5 (YP_258358); ChiG, ChiG of Streptomyces coelicolor A3(2) (BAA75648); ChiC, ChiC of S. griseus HUT 6037 (BAA23739); Jackbean, class II chitinase of Canavalia ensiformis (CAA07413); and Barley, class II chitinase of Hordeum vulgare (P23951). 
375 Figure 2. Hydrolytic activity for various chitooligosaccharides using the culture

376 supernatant from E. coli cells expressing the wild-type ORF69 and its mutants. The

377 reaction mixture was $2.5 \mathrm{mM}$ substrate, $50 \mathrm{mM}$ sodium phosphate buffer (pH6.2) and

378 mixed with $100 \mu \mathrm{g}$ of the culture supernatant. pNP-(GlcNAc $)_{2}$, white bars;

379 pNP-(GlcNAc) $)_{3}$, pale-grey bars; pNP-(GlcNAc) $)_{4}$, dark-grey bars; and pNP-(GlcNAc),

380 black bars. The reaction mixtures were incubated for $15 \mathrm{~min}$ in $50 \mathrm{mM}$ sodium

381 phosphate buffer (pH6.2) at $37^{\circ} \mathrm{C}$. The bars are an average of three independent measurements. N.D: Not detected. 
$383 \quad$ Fig.1

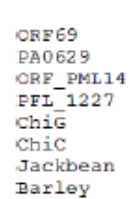

Parley

ORF 69

PA0629

ORE_PML14

PFI 1227

$\mathrm{ChiG}$

Chic

Jackbean

ORF 69

A 0629

ORF_PML1 1

PFI_1227

Chic

Jackbean
Barley

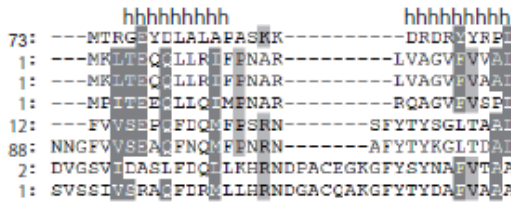

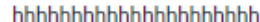

hhhhhhhhhh AAMEECNIKGPARAMDERE ID PA-BMAMMAKRII A

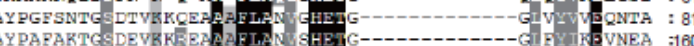

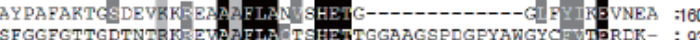

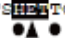
A

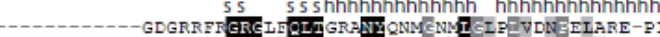

S $\begin{array}{ll} & \end{array}$

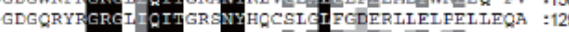

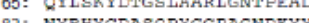

82. NYAHCDASLPYGCPGMLKY -

Q4: -SNKYCDPG--TPCPAG-RSYY

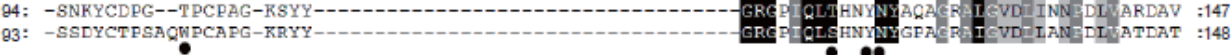

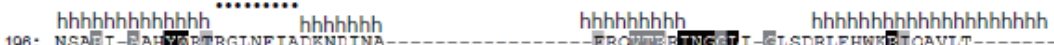

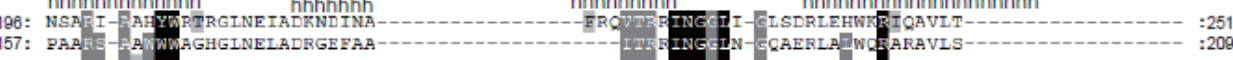
157: PARES-

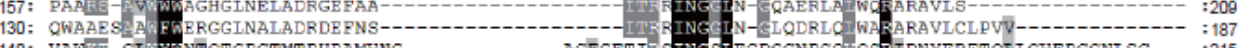

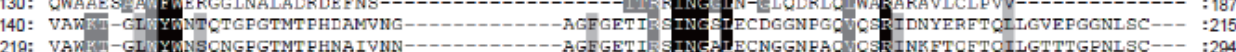

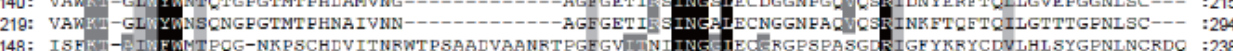

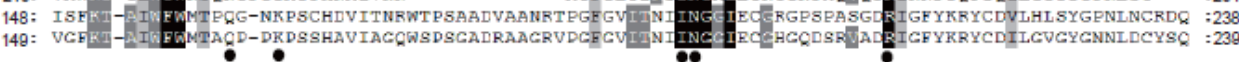


385 Fig. 2

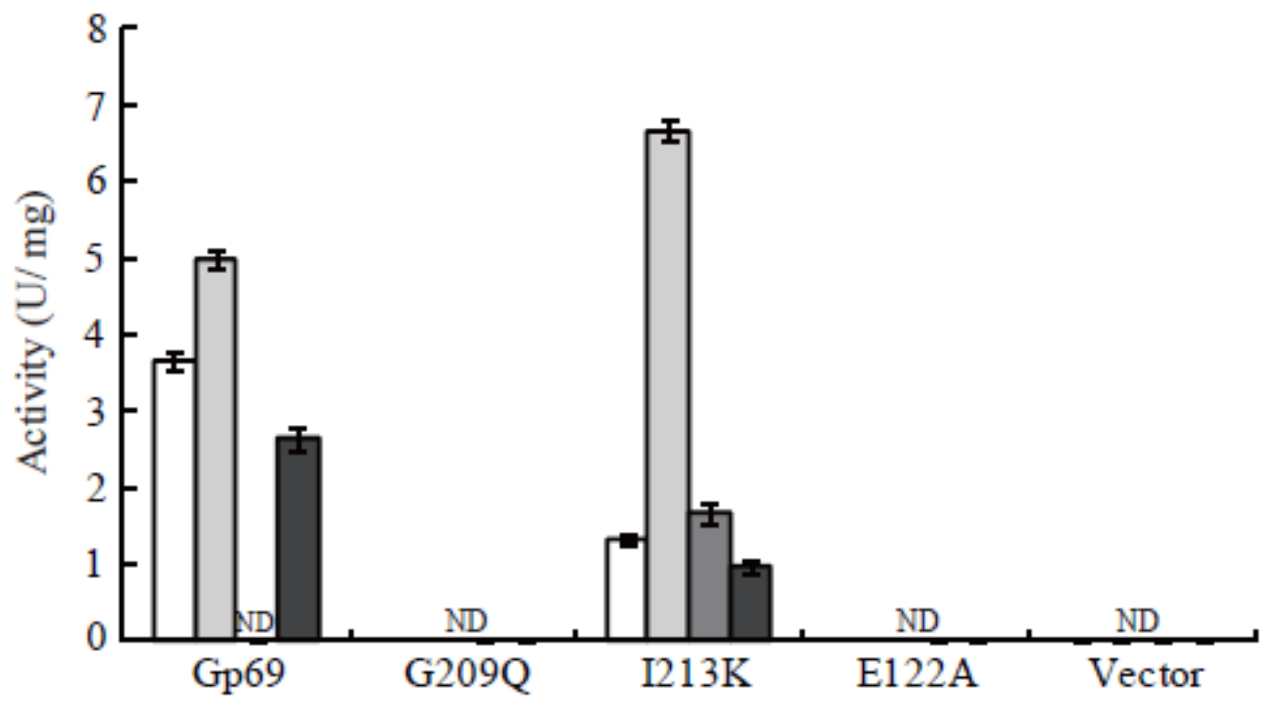

386 